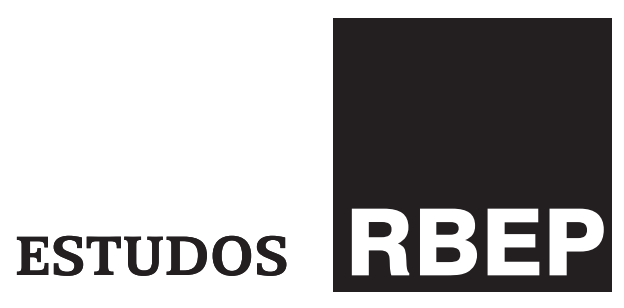

\title{
A universidade na sua constituição: criação, reformas e implicações político-epistemológicas
}

Gildo Volpato

\section{Resumo}

Revisa e apresenta o resultado de estudo bibliográfico sobre os aspectos históricos, políticos e epistemológicos que motivaram a criação, as reformas e o modo de atuação das universidades brasileiras. Aponta aspectos históricos que ajudam a entender a atitude do Estado brasileiro em adotar uma posição de avaliador depois da LDB. Reflete sobre a trajetória da universidade brasileira e diz que houve ações que marcaram o atual ensino superior em nosso País. Conclui que a universidade é uma instituição social não acabada, que continua sendo ressignificada em cada tempo e contexto, tendo em vista os atores sociais, as bases epistemológicas e os condicionantes culturais, políticos e econômicos que a produzem.

Palavras-chave: universidade; reformas; políticas; Estado; avaliação. 


\section{Abstract \\ The university and its constitution: creation, reform and political- epistemological implications}

This study reviews the results of a bibliographic study concerning the historical, political and epistemological aspects that motivated the creation, the reforms and the Brazilian universities actuation. It shows historical aspects that enable the understanding of the Brazilian state attitude towards the adoption of an evaluator position after the National Educational Bases and Guidelines Law. There is a reflection concerning the Brazilian university pathway and an indication that there were actions that affected the present higher education system in Brazil. It concludes that a university is a social institution that has not come to an end, it is being resignified according to times and contexts, taking into account social actors, epistemological bases and cultural, political and economical conditions.

Key words: university, reforms, policies, State, evaluation.

\section{Introdução}

O objetivo deste artigo de revisão é apresentar o resultado de um estudo bibliográfico que teve como intuito conhecer e compreender os aspectos históricos, políticos e epistemológicos que motivaram a criação, as reformas e a forma de atuação das universidades brasileiras.

Recuperar a trajetória da universidade no Brasil constitui-se uma tarefa desafiadora, tantas e tão complexas são as dimensões implicadas no processo de desenvolvimento do ensino superior em nosso País.

É importante começar registrando a missão eterna da universidade, para, a partir dela, analisar os movimentos e as razões que motivaram as reformas, sua expansão e as tensões históricas que se colocam perante seus objetivos, princípios e valores.

Das instituições sociais laicas no mundo ocidental, a universidade, sem dúvida, é a mais contínua e duradoura. Se sobreviveu durante nove séculos como uma instituição macrossocial imprescindível, é, sobretudo, devido à sua grande capacidade de preservar sua forma de organização estrutural e, ao mesmo tempo, se renovar continuamente, sem, entretanto, descaracterizar sua natureza ou deixar de se preocupar com seus princípios essenciais. No entender de Dias Sobrinho (2005, p. 29), essa solidez que atravessa os tempos se deve a duas características contraditórias, pois 
[...] de um lado, a universidade guarda uma forte tendência a resistir às mudanças e de assegurar a unidade, por outro lado, ela apresenta grande flexibilidade, capacidade de adaptação às demandas que vão surgindo e abertura à diversidade. A universidade tem sobrevivido a todas as mudanças sociais porque, ainda que erre e falhe, também tem enorme capacidade de se superar, de se adaptar, de se transformar e de pensar o futuro.

No dizer de Jaspers (apud Sousa Santos, 1999, p. 188), a universidade tem como missão eterna ser "o lugar onde, por concessão do Estado e da sociedade, uma determinada época pode cultivar a mais lúcida consciência de si própria". Nela, seus membros congregam-se com o objetivo único de buscar, incondicionalmente, a verdade e apenas por amor à verdade. A partir desse entendimento decorreriam, por ordem decrescente de importância, como afirma Sousa Santos (1999), baseando-se em Jaspers, os três grandes objetivos da universidade: a investigação, seu principal objetivo, porque a verdade só é acessível a quem a procura sistematicamente; a cultura, disponível para a educação do homem no seu todo, já que o âmbito da verdade é muito maior do que o da ciência; e, por último, a verdade que deve ser preservada - é por isso a universidade ensina, e mesmo o ensino voltado às aptidões profissionais deve estar orientado para a formação integral do indivíduo.

\section{A universidade brasileira: aspectos históricos e conceituais}

A dependência cultural, principalmente em relação aos países da Europa, marcou profundamente a história do ensino superior no Brasil, uma vez que, conforme Wanderley (1983, p. 33), "tudo se resumia em copiar o que se produzia nas universidades europeias, passando pelas ideias liberais e positivistas, que formaram a ideologia de muitos estudantes e professores e que influenciaram os setores progressistas das classes dominantes e médias".

Até 1808, os luso-brasileiros faziam seus estudos superiores na Europa, principalmente em Coimbra, Portugal. O retardo na criação de faculdades e universidades é compreendido pelas características da política colonialista predominante. A Coroa de Portugal preferia que as elites fossem à Europa a fim de educar-se e lá realizar seus estudos superiores.

A Universidade de Coimbra acolhia os filhos da elite portuguesa que nasciam nas colônias, visando desenvolver uma homogeneidade cultural, avessa a questionamentos à fé católica e reforçando a ideia de superioridade da metrópole em relação à colônia. No dizer de Anísio Teixeira (1989), Coimbra foi a "primeira universidade" para os brasileiros, pois nela se graduaram mais de 2.500 jovens nascidos no Brasil, durante os três primeiros séculos de nossa história.

Com a chegada de D. João VI ao Brasil, foi instituído o ensino superior em forma de faculdades isoladas. Nasceram os cursos e as academias com o objetivo de dar resposta às necessidades da Colônia, advindas da 
${ }^{1}$ Conforme Fávero (2000), essa academia foi o núcleo inicial da atual escola de engenharia da Universidade Federal do Rio de Janeiro (UFRJ).

${ }^{2}$ Instituições seculares mais voltadas ao ensino do que à pesquisa. instalação da Corte no Rio de Janeiro. Em 1808, foram criadas a escola anatômica, cirúrgica e médica do Rio de Janeiro e a escola do curso médico de cirurgia da Bahia, como resultado da evolução de cursos de anatomia, cirurgia e medicina, ministrados de forma isolada durante a época colonial (Fávero, 2000).

Em 1810, pela Carta Régia de 4 de dezembro, foi instituída a Academia Real Militar, ${ }^{1}$ inaugurada em abril de 1811, com o objetivo voltado, em especial, para a formação de oficiais e engenheiros civis e militares, o que, de certo modo, deveria contribuir para o desenvolvimento e a defesa militar da colônia, então sede da Monarquia.

O objetivo básico, na época, era a formação especializada e a preparação dos estudantes para que pudessem ser úteis, principalmente ao serviço público. Além de seu caráter prático e imediatista, as escolas superiores se resumiam a atender uma parte limitada do território nacional, ou seja, basicamente a Bahia e o Rio de Janeiro. Não havia empenho para a criação de uma universidade, pois se receava que a universidade facilitasse o rompimento dos laços que uniam a sociedade brasileira à Corte de Lisboa. Nesse sentido, o ensino superior, de caráter elitista, vinculava-se aos interesses dos colonizadores, atendendo à minoria da população.

O processo de transposição cultural, ligado sempre aos interesses do colonizador, foi forte em nosso País, se comparado ao que ocorreu nos países latino-americanos colonizados pelos espanhóis.

Ribeiro (1975) afirma que o modelo adotado no Brasil, como inspirador da organização curricular dos cursos, foi a concepção francesa da universidade napoleônica, principalmente em relação às características de escola autárquica, com a supervalorização das ciências exatas e tecnológicas, voltadas para a profissionalização, e a desvalorização da filosofia, da teologia e das ciências humanas.

Desde seu início, os cursos superiores e as faculdades criadas e instaladas no País preocuparam-se fundamentalmente com a formação de profissionais que respondessem às demandas e às necessidades existentes. Os cursos estruturavam-se em currículos seriados, com programas fechados, contemplando unicamente disciplinas que interessavam diretamente ao exercício de cada profissão. O objetivo era formar profissionais competentes em uma determinada área ou especificidade.

Em 1827, conforme Fávero (2000), foram instituídos os cursos jurídicos no Brasil, pelo imperador D. Pedro I, quando, em assembleia geral sancionou a Carta de Lei, de 11 de agosto. Um deles passou a funcionar no Convento de São Francisco, em São Paulo, e o outro no Mosteiro de São Bento, em Olinda, depois transladado para Recife.

As primeiras faculdades brasileiras - direito, medicina e politécnica - seguiam o modelo das grandes escolas francesas. ${ }^{2}$ Eram independentes umas das outras, possuíam uma orientação profissional bastante elitista e estavam localizadas nas cidades consideradas mais importantes. Como diz Olive (2002, p. 32), "tanto sua organização didática como sua estrutura de poder baseavam-se em cátedras vitalícias: o catedrático, 'lente 
proprietário', era aquele que dominava um campo de saber, escolhia seus assistentes e permanecia no topo da hierarquia acadêmica durante toda a sua vida".

Essa ideia de propriedade da cátedra vai se fazer presente na história de nossas instituições de ensino superior durante mais de um século. Os estatutos que regulamentavam os cursos jurídicos, por exemplo, previam que

[...] os professores teriam todas as honras e prerrogativas de que gozavam os da Universidade de Coimbra, regendo as cadeiras para cujas matérias se reputarem mais aptos, podendo passar de uma para as outras, quando isto convier ao aproveitamento dos que frequentarem os cursos jurídicos (Venâncio Filho, 1977, p. 36).

Com essa prerrogativa, o professor catedrático adquiria vitaliciedade, passando a ser o primeiro na hierarquia do corpo docente, até sua aposentadoria ou morte. Essa ideia de cátedra se estende por toda a universidade e ganha força nas futuras reformas do ensino superior no Brasil, até ser extinta por força da Lei $n^{\circ}$ 5.540, de 1968.

No período imperial, não foram criadas universidades no Brasil. O alto conceito que se tinha, na época, da Universidade de Coimbra talvez pudesse, em certa medida, ter dificultado sua substituição por uma instituição tão jovem como as do Brasil.

Por volta de 1900, estava consolidado no Brasil o ensino superior, em forma de faculdades ou escolas superiores. No início da Primeira República, no Brasil havia 14 escolas superiores, conforme afirmam Carneiro e Carneiro (2000).

Também no período republicano, a criação de universidades no Brasil enfrentou dificuldades, tendo em vista a influência do ideario positivista ${ }^{3}$ que orientou a nova fase política. A universidade, por ser uma instituição medieval voltada às necessidades do Velho Continente, era considerada, pelos líderes políticos da Primeira República (1989-1930), ultrapassada e anacrônica para atender às necessidades do Novo Mundo. Por conta disso, defendiam a criação de cursos laicos de orientação técnica profissionalizante.

Com a Lei Orgânica Rivadávia da Cunha Correia, Decreto 8.659, de 5 de abril de 1911 (Brasil, Decreto, 1911), os estabelecimentos de ensino, até mesmo os públicos, passaram a ser corporações autônomas, quer em nível didático, quer administrativo, com personalidade jurídica própria, podendo receber subvenções e doações do poder público ou de outra origem qualquer, resolvendo, de modo próprio, currículos, programas e exames. Foi instituída a livre-docência, conquistada por apresentação de tese, sem defesa. Os professores eram classificados em ordinários e extraordinários.

A criação da primeira universidade brasileira só foi possível a partir do Decreto no 11.530, de 18 de março de 1915, da Reforma Carlos Maximiliano (Brasil, 1915). No entanto, a Universidade do Rio de Janeiro, primeira universidade criada pelo governo central, só se tornou realidade

\footnotetext{
3 Doutrina preconizada por Augusto Comte, que consiste em aplicar, nas ciências sociais, os mesmos métodos e leis aplicáveis às ciências naturais.
} 
cinco anos mais tarde, em 7 de setembro de 1920, pelo Decreto n ${ }^{\circ} 14.343$ (Brasil, 1920).

O fato de a UFRJ ter sido criada a partir da união da escola politécnica, da faculdade de medicina e de uma das faculdades livres de direito, pelas histórias individuais de cada uma delas, apresentava poucos pontos de referência que unissem as concepções acadêmicas das distintas faculdades, prejudicando a concepção universitária. Mesmo assim, o ato de criação da universidade estimulou as discussões a respeito da estrutura e do papel que a universidade deveria representar perante a sociedade. Na época, começavam a surgir algumas reações antipositivista e passaram a ser debatidas, nos círculos acadêmicos, questões referentes à pesquisa e ao ensino superior. A criação da Associação Brasileira de Educação (ABE), em 1924, favoreceu a continuidade de tais discussões, culminando na publicação do livro O problema universitário brasileiro, baseado em entrevistas com professores do ensino superior de diversos Estados. Uma das metas principais da associação era a criação do Ministério da Educação (Schwartzman, 1982).

Ao término da Primeira República, o Brasil possuía cerca de 200 estabelecimentos de ensino superior, considerando as escolas de formação militar e teológica e duas universidades, a do Rio de Janeiro (1920) e a de Minas Gerais (1927).

Depois de 1930, percebe-se o esforço para a transformação do ensino superior no Brasil, principalmente a partir do reconhecimento legal de que a junção de três ou mais faculdades poderia caracterizar-se como uma universidade. Já havia, nessa época, preocupação com que a universidade superarasse a lógica do simples agrupamento de faculdades, estimulando maior interação e uma relação mais comprometida entre elas, com a busca de soluções para os problemas apresentados pela sociedade (Luckesi, 1985).

As universidades, até então, nas palavras de Nagle (1974, p. 109), "isoladas com o mínimo de comunicação com a sociedade, encerravam-se intramuros, visando à transmissão dogmática de conhecimentos e à formação de tipos letrados que se transformavam, pela prática rotineira, em políticos, oficiais, administrativos, homens de negócios e profissionais liberais".

Norteados pelos ideais pedagógicos e sociais próprios da sociedade urbana e industrial que se consolidava no País, surgem movimentos e novas diretrizes para a educação na época. Com o intuito de se opor a uma série de reformas parciais que ocorreram sem o devido encadeamento com as reformas econômicas e sem atender às necessidades do País, emerge o movimento dos Pioneiros da "Escola Nova". O movimento apontava uma defasagem entre o sistema econômico e o sistema educacional, dado o isolamento e o distanciamento da escola ou da universidade em relação ao seu ambiente e contexto.

Ao abordar o problema da educação e expor o conceito moderno de universidade, os responsáveis pelo encaminhamento da "Educação Nova" deixaram claras três funções que deveriam ser desempenhadas 
pela universidade, apontadas por Silveira (1987): a de ser criadora de ciência, a de assumir a responsabilidade com a formação de docentes e a de ser popularizadora das ciências e das artes por meio da extensão universitária. Havia a intenção de extrapolar o papel até então desenvolvido pela universidade, o de preparar profissionais para o exercício legal e técnico, principalmente para as profissões liberais.

A política educacional proposta era reflexo da sociedade emergente, que oscilava entre a necessidade de inovar e de organizar a vida social sob novas bases e a velha ordem, com a qual ainda se encontrava seriamente comprometida. Essas tensões foram citadas por Romanelli (1978, p. 142):

As classes, que iam gradativamente assumindo o poder, contavam entre si com a presença, de um lado, dos jovens oficiais progressistas e da nova burguesia industrial, que exigiam inovações de toda a ordem, mas, de outro lado, contavam também com a presença de parte da velha aristocracia liberal, ainda apegada às velhas concepções. A expansão do ensino e sua renovação ficaram, portanto, subordinadas ao jogo de forças que essas camadas manipulavam na estrutura do poder.

Essa nova proposta foi muito criticada pelos setores conservadores, ligados à Igreja Católica, pois temiam a influência do liberalismo norte-americano, considerada por eles negativa por ser "materialista, individualista e protestante sobre os valores católicos, humanistas e personalistas, considerados essenciais à cultura brasileira", como afirma Olive (2002, p. 35).

O processo de industrialização e o desenvolvimento econômico, iniciados a partir de 1920, se aceleraram nas décadas posteriores, culminando, no início da década de 1960, com uma grande demanda de mão de obra especializada. Cresciam as ofertas de trabalho nas indústrias, cujos serviços demandavam maior qualificação profissional. Houve, então, uma expansão significativa do ensino superior. De 1945 a 1960, foram criadas mais de 223 Instituições de Ensino Superior (IES), iniciando-se a década de 1960 com um total de 404 delas (Carneiro; Carneiro, 2000). Entretanto, em sua maioria, elas ainda se caracterizavam mais como escolas e faculdades do que como universidades.

Durante a Nova República, 22 novas universidades federais foram instaladas, formando o sistema de universidades federais. Cada um dos Estados da Federação passou a contar com, pelo menos, uma universidade federal localizada na capital. Nesse mesmo período, foram criadas, ainda, oito universidades católicas e uma presbiteriana.

A ideia de se criar uma universidade brasileira, a partir da reflexão nacional, com base nos problemas nacionais, que fosse uma universidade livre, criadora e crítica, tal como sonhava Anísio Teixeira, desde 1935, continuou depois da ditadura do Estado Novo e ganhou força depois dos anos de 1960, com a liderança de Darcy Ribeiro, inspirador da Universidade de Brasília (UnB). Esta começou a funcionar em 21 de abril de 1962, tendo como principais objetivos o desenvolvimento de uma cultura e de uma tecnologia nacionais ligadas ao projeto desenvolvimentista. Foi 
a primeira universidade brasileira criada com uma estrutura integrada, flexível e moderna, contrapondo-se à universidade segmentada em cursos profissionalizantes. Essa força renovadora, inspiradora de uma nova forma de ser e de fazer universidade, vinculada e comprometida com o seu tempo e com seu contexto, foi logo sepultada pelo novo regime implantado no País a partir de 1964.

Nesse ano, depois de os militares tomarem o poder, as universidades passaram a ser objeto de uma ingerência direta do governo federal. Nessa época, foram afastados de suas funções muitos professores. A ideologia de "Segurança e Desenvolvimento" sustentava a ideia de nação, sendo o crescimento econômico enfatizado pelo grupo que passou a deter o poder. O intento principal foi o de alijar a universidade de seu papel político e ideológico. Dissolveu-se a União Nacional dos Estudantes (UNE) e proibiu-se, por Atos Institucionais, o exercício cidadão e associativo. A universidade ficou vigiada, afastando-se os que "ameaçavam" a ordem institucional.

Entretanto, a demanda social pela educação superior crescia e a universidade, baseada nas clássicas faculdades profissionais, não estava apta para atender às novas exigências das classes emergentes e do projeto nacional. Uma nova identidade para a universidade começou a se definir na segunda metade da década de 1960. A universidade seria a instituição própria do ensino superior e as faculdades isoladas seriam admitidas como exceção. Nas universidades, o ensino seria indissociável da pesquisa, que se desenvolveria de preferência nos programas de pós-graduação. O regime de cátedras foi extinto e, em seu lugar, foram implantados os departamentos. A Lei no 5.539/1968 (Brasil, 1968) modificou o Estatuto do Magistério das Instituições Federais de Ensino Superior. A progressão na carreira docente considerou os graus acadêmicos de mestre e de doutor, além de incluir o trabalho em tempo integral, que ganhou incentivo, visando a fixar os professores-pesquisadores na universidade.

A extinção do regime de cátedras, em 1968, favoreceu a emergência da pós-graduação brasileira. Na visão de Antonio Cunha (1998), foi a pesquisa e os cursos de mestrado e doutorado, impulsionados pelo aporte de recursos para essa finalidade, sem a intermediação das reitorias, que propiciaram a formação de uma nova identidade para a universidade brasileira.

Mesmo que alguns elementos dessa reforma fossem mais tarde atenuados ou até anulados em sua implementação, não se pode deixar de reconhecer sua importância, e até coerência, num quadro de mudança da identidade da universidade brasileira. Essa mudança de identidade não ocorreu sem crise, mas os conflitos que poderiam resultar dela foram logo abafados pela contenção político-ideológica dos governos militares.

Embora a reforma fosse para as instituições federais, como grande parte do setor privado também dependia de subsídios governamentais, ela acabou atingindo as instituições, que procuraram, em alguma medida, adaptar-se às suas orientações.

A Reforma de 1968 sofreu forte influência do modelo norteamericano. Com o regime militar, o modelo europeu perdeu sua força, e as relações com o governo norte-americano constituíram-se o referencial 
para definir políticas educativas. Acordos bilaterais, como o conhecido MEC/Usaid ${ }^{4}$ deram sustentação aos planos dos militares e representaram as políticas sociais, em especial na educação, produzindo e orientando práticas no nível superior e no ensino fundamental e médio no País, tomando por base as ideias de racionalidade, produtividade e eficiência, que são características inspiradoras da pedagogia tecnicista.

A partir de um olhar que ultrapassa as fronteiras de um país, a aparente perenidade de objetivos da universidade começou a ser abalada, na percepção de Sousa Santos (1999), tendo em vista as grandes pressões e as transformações que sobre ela se abateram. A partir de então, os três fins da universidade - a investigação, a cultura e a verdade - foram redefinidos e passaram a ser a investigação, o ensino e a prestação de serviço. Houve um atrofiamento da dimensão cultural da universidade e um privilegiamento do seu conteúdo utilitário e produtivista, que resultou numa multiplicidade de funções muitas vezes contraditórias.

Para Mendes (apud Araújo, 1984, p. 131), o Estado teria criado, a partir da Reforma de 1968, o "desvio tecnológico substituindo a ratio política pela ratio técnica e na estratégia despolitizante usava a técnica do compartimentismo". No contexto da reforma, a racionalização, a eficiência e a produtividade tornaram-se valores principais, tendo validade em si e por si mesmas. Outra questão é que a modernização acabou criando uma complexidade administrativa, incluindo uma série de mecanismos para maior controle dentro e fora da universidade. Essa condição a tornou mais conservadora na sua estrutura geral.

Anísio Teixeira (1969, p. 235) dizia que a universidade brasileira,

[...] além de preparar profissionais para as carreiras liberais e técnicas que exigem uma formação de nível superior, o que tem havido é uma preocupação muito fluída com a iniciação do estudante na vida intelectual. Daí poder-se afirmar que, ressalvando o aspecto habilitação profissional, a universidade brasileira não logrou constituir-se verdadeiramente como uma instituição de pesquisa e transmissora de uma cultura comum nacional, nem logrou se tornar um centro de consciência crítica e de pensamento criador.

Chaú (2001, p. 189) chama de "universidade funcional" a atuação das universidades nos anos de 1970 e, como ela diz, "foi o prêmio consolação que a ditadura ofereceu à sua base de sustentação político-ideológica, isto é, à classe média despojada de poder", a quem foi prometido prestígio e ascensão social por meio do diploma universitário. A massificação operada resultou na abertura indiscriminada de cursos superiores. Essa universidade estava preocupada com a formação rápida de profissionais requisitados como mão de obra altamente qualificada para o mercado de trabalho. No entendimento da autora, para adaptar-se às exigências do mercado, a universidade alterou seus currículos, programas e atividades, para garantir a inserção profissional dos estudantes no mercado de trabalho.

A Reforma de 1968 refletiu o alinhamento da educação superior ao modelo econômico, vinculado à internacionalização do capital e sustentado pelo governo militar.
${ }^{4}$ Ministério da Educação e Cultura (MEC) e United States Agency Internacional of Devolopment (Usaid). 
No entender de Hawerroth (1999), as ações emanadas dessa reforma trouxeram como resultado uma expansão desordenada, uma vez que o Conselho Federal de Educação (CFE) afrouxou as exigências para a autorização de novas instituições privadas de ensino superior.

Apesar da pertinência das críticas, persistiu o princípio básico da não duplicação dos meios para fins idênticos ou equivalentes e houve grande expansão de matrículas nas universidades brasileiras. Como aponta Araújo (1984), o número de matrículas no ensino superior, que em 1968 era de 278.295, cresceu para 1.311.799 em 1979. Essa expansão fez com que, no ano de 1980, mais da metade dos alunos de terceiro grau estivesse matriculada em estabelecimentos isolados de ensino superior, sendo 86\% em faculdades privadas.

Os governos militares viam com bons olhos a expansão do setor privado, pois, segundo sua ótica, com a pulverização de faculdades, haveria mais dificuldade para os alunos se mobilizarem.

Nesse período, foi dada importância à pós-graduação e à pesquisa, visando a potencializar o desenvolvimento econômico por meio da formação de recursos humanos de alto nível, para atender às demandas decorrentes do avanço do processo de modernização da sociedade. Para esse fim, foram escolhidas as maiores e mais tradicionais universidades públicas, onde foram criados cursos de mestrado e, mais tarde, de doutorado. A formação dos quadros docentes que protagonizaram esse movimento foi realizada por universidades americanas, que, dessa forma, garantiam sua influência nos formatos da pós-graduação brasileira.

O início da década de 1980 evidenciou o esgotamento dos efeitos do chamado "milagre econômico brasileiro", encaminhando o fim do regime militar e favorecendo a revitalização dos movimentos sociais no País. É nessa nova conjuntura que a abertura política se amplia, tendo como suporte e, ao mesmo tempo, dando suporte à nova Constituição de 1988. Curiosamente, como afirma Corbucci (2004), os mais diversos avanços nos campos político e social, constantes na nova Constituição, foram estabelecidos sob um contexto de retração da atividade econômica, resultando na diminuição da capacidade de investimentos do Estado nas diversas áreas e, em particular, no ensino superior. Foi nesse contexto, por um lado promissor pelas possibilidades de discussão e de avanços, que foi interrompido o processo de expansão física da Rede Federal de Ensino Superior, que estava em curso até o final da década de 1970.

A partir das dificuldades de investimentos, por parte do Estado, para as universidades, estas, para poder continuar atendendo às expectativas de uma sociedade cada vez mais exigente e em constante mudança, tiveram de ampliar suas relações com o mundo empresarial, no sentido de prestação de serviços e possibilidades de estágio para seus alunos.

Chauí (2001) caracteriza o período de atuação dos anos de 1980 como o período da "universidade de resultados", pela crescente expansão das escolas privadas de ensino superior, encarregadas de continuar alimentando o sonho social da classe média, e pela introdução da ideia de parceria entre a universidade pública e as empresas privadas. Esse 
aspecto foi decisivo, na medida em que as empresas não só deveriam assegurar o emprego aos futuros profissionais e estágios remunerados aos estudantes, como ainda financiar pesquisas diretamente ligadas a seus interesses. Como diz a autora, "eram os empregos e a utilidade imediata das pesquisas que garantiam à universidade sua apresentação pública como portadora de resultados" (Chaúí, 2001, p. 190).

Nos debates que antecederam a promulgação da Constituição Brasileira de 1988, duas correntes podem ser identificadas: de um lado, aqueles que se identificavam com os interesses da educação pública e gratuita e, de outro, os que estavam ligados ao setor privado, interessados em obter acesso a verbas públicas e diminuir a interferência do Estado nos negócios educacionais. Essas duas correntes, de certa forma, continuam em tensão no contexto atual.

Em consonância com o discurso da modernização que pautou o projeto político do primeiro governo, referendado pelas urnas, depois do regime militar, caberia às instituições de ensino superior a formação de recursos humanos demandados por um mercado cada dia mais competitivo. Esse mercado se forjava a partir da almejada inserção do Brasil no chamado Primeiro Mundo, articulado com os organismos internacionais. A esse período de atuação característico dos anos 1990, Chauí (2001) chamou de "universidade operacional". Enquanto a "universidade clássica" estava voltada para o conhecimento e a "universidade funcional" se voltava diretamente para o mercado de trabalho, a "universidade de resultados" se voltava para os interesses das empresas. Já a "universidade operacional", por ser uma organização, estaria voltada para si mesma como estrutura de gestão. Nas palavras da autora,

[...] regida por contratos de gestão, avaliada por índices de produtividade, calculada para ser flexível, a universidade operacional está estruturada por estratégias e programas de eficácia organizacional e, portanto, pela particularidade e instabilidade dos meios e objetivos.

(Chauí, 2001, p. 190).

Ainda, conforme a autora, na universidade operacional, produtiva e flexível, a docência era entendida como a transmissão rápida de conhecimentos, tendo como prática o uso de manuais de fácil leitura para os estudantes, preferencialmente, ricos em ilustrações e com duplicata em CDs.

As políticas educacionais traduzidas pelas reformas educacionais, implementadas a partir de 1990 até o início de nossa década, no Brasil, procuraram traduzir as demandas postas pela lógica do capital, respondendo às exigências emanadas dos organismos internacionais. Para Maués (2006, p. 295), "a crise mundial do estado capitalista, que se manifestou de forma evidente a partir dos anos 70, gerou a necessidade de se buscar saídas que permitissem a retomada dos objetivos de crescimento econômico, propiciando o surgimento de um novo modelo de acumulação." Para os Estados periféricos, a crise foi vista como do Estado e não do capital. Foi no bojo da reforma do Estado, para se adequar às novas exigências, que a educação foi classificada como um serviço não exclusivo do Estado. 
Da mesma forma, a chamada "revolução tecnológica", que se materializa no mesmo período da crise, muitas vezes sendo apontada como um dos motivos da própria crise, produz uma reestruturação produtiva, alterando a organização do processo de produção e modificando a estrutura e as relações do trabalho.

É nesse contexto que começam a ser definidas as reformas na educação brasileira na última década, tendo continuidade nos primeiros anos do novo milênio. As características dessas reformas são as de regulação e controle, em função das características que o Estado assumiu, as de um Estado avaliador.

Chauí (2001, p. 182) afirma que, quando

[...] a Reforma do Estado transforma a educação de direito em serviço e percebe a universidade como prestadora de serviços, confere um sentido bastante determinado, a ideia de autonomia universitária, e introduz o vocabulário neoliberal para pensar o trabalho universitário, como transparece no uso de expressões como "qualidade universitária", "avaliação universitária" e "flexibilização da universidade".

Para atender às múltiplas exigências de um mundo cada vez mais globalizado e competitivo e, ao mesmo tempo, manter uma relação aparentemente democrática e de inclusão da maioria da população, caberia à universidade ampliar suas funções e seus objetivos.

O relatório da Organização para a Cooperação e Desenvolvimento Econômico $(\mathrm{OCDE})^{5}$ atribuía à educação pós-secundária as funções principais: investigação; fornecimento de mão de obra qualificada; educação e treinamento altamente especializados; fortalecimento da competitividade da economia; mecanismo de seleção para empregos de alto nível mediante credencialização; mobilidade social para os filhos e filhas das famílias operárias; prestação de serviços à região e à comunidade local; paradigmas de aplicação de políticas nacionais (exemplo: igualdade de oportunidade para mulheres e minorias raciais); e preparação para os papéis de liderança social (Sousa Santos, 1999, p. 189).

Com essa multiplicidade de funções, cabe perguntar se é possível e compatível desenvolvê-las, por uma mesma instituição, sem que haja choque, colisão, contradição. Para Sousa Santos (1999), a contradição é uma das características que mais marcam as universidades nos tempos atuais. No domínio da investigação, o interesse científico pode ser muito diferente do interesse em fortalecer a competitividade econômica. No ensino, os objetivos da formação geral e da preparação cultural podem colidir, no interior da mesma instituição, com os da formação profissional ou da educação especializada.

Dias Sobrinho (2005, p. 33) reforça essa posição dizendo que a contradição é um elemento constituinte da universidade. Em suas palavras: "como tudo o que é social, a educação superior vive e produz grandes contradições. A cada tempo e em cada lugar, vive as tensões da sociedade e responde a muitas de suas demandas, ora com mais, ora com menos autonomia, porém jamais imune às contradições". 
Essas contradições criam sempre tensões, tanto no relacionamento das universidades com o Estado e a sociedade, como no interior das próprias universidades, como instituições e organizações. Enquanto não for possível superar essas contradições, o objetivo das reformas propostas à universidade tem sido, fundamentalmente, o de manter as contradições sob controle mediante a gestão das tensões.

No entendimento de Sousa Santos (1999), a gestão das tensões tem sido problemática, principalmente em três questões: a contradição entre a produção de alta cultura e de conhecimentos, que ele chama de exemplares, necessários à formação das elites, presente na tradição da universidade desde a Idade Média, e a produção de padrões culturais médios e de conhecimentos úteis e práticos para as tarefas de transformação social e para a formação da força de trabalho qualificada, exigida pelo desenvolvimento industrial; a contradição entre a hierarquização dos saberes especializados, por meio das restrições do acesso e da credencialização das competências e das exigências sociopolíticas da democratização e da igualdade de oportunidades; e, por último, a contradição entre a conquista da autonomia na definição dos valores e dos objetivos institucionais e a submissão crescente a critérios de eficácia e de produtividade de origem e de natureza empresarial.

Pelo fato de a gestão de tensões não dar conta de intervir nas causas mais profundas das contradições, o resultado é sempre, como diz Sousa Santos (1999), uma dada crise da universidade, que ele classifica em "crise de hegemonia, crise de legitimidade e crise institucional".

A "crise de hegemonia" é resultante da primeira contradição, entre a produção de conhecimentos exemplares e de conhecimentos úteis, práticos. Ocorre sempre quando uma dada condição social deixa de ser considerada necessária, única e exclusiva. Nesse sentido, a universidade sofre uma crise de hegemonia, na medida em que sua incapacidade de atender a todas as exigências externas, muitas vezes contraditórias, faz com que os interessados procurem outros meios para atingir seus objetivos.

A "crise de legitimidade" ocorre sempre que uma dada condição social deixa de ser consensualmente aceita. Esta crise é oriunda da contradição entre hierarquização e democratização. É uma crise na medida em que torna socialmente visível a falência dos objetivos coletivamente assumidos.

A terceira contradição, entre autonomia institucional e submissão à produtividade empresarial, manifesta-se como "crise institucional". Ocorre sempre que uma dada condição social estável e autossustentada deixa de garantir os pressupostos que asseguraram sua reprodução. A universidade sofre uma crise institucional à proporção que sua especificidade organizativa é posta em cheque e passam a ser impostos modelos de organização e de gestão vigentes em outras instituições tidas como mais eficientes.

\section{A universidade brasileira depois da LDB}

Na década de 1990, houve alterações no papel do Estado em relação às universidades, o que resultou em mudanças significativas nos seus 
modos de atuação, pela Lei de Diretrizes e Bases da Educação Nacional (LDB), no 9.394/96.

A nova LDB reconheceu diferentes categorias de educação superior e classificou as instituições dividindo-as em universidades, centros universitários e faculdades isoladas. As universidades, além do ensino, devem atuar na pesquisa e extensão. Essa condição não é exigida para os centros universitários e faculdades isoladas, que podem centrar seus esforços nas atividades de ensino. Outra exigência para as universidades é a de que devem ter, no mínimo, um terço do seu corpo docente com titulação de mestres ou doutores, além da exigência de manterem em seus quadros um terço de docentes em tempo integral.

Por força de lei, as instituições de ensino superior, principalmente as universidades, trataram de buscar alternativas para atender a essas exigências, incentivando seus docentes a se qualificarem. Tiveram, ainda, que contratar profissionais com a titulação de mestres e doutores, além de ampliarem a carga horária de um determinado número de docentes, possibilitando iniciar ou ampliar as atividades de pesquisa e extensão.

A LDB, em seu artigo 66, diz claramente que a preparação para o exercício do magistério superior far-se-á em nível de pós-graduação, prioritariamente em programas de mestrado e doutorado. Nesse sentido, a Lei assevera, como afirma Cury (2006, p. 275), "que o exercício do magistério superior não é um campo para diletantes, voluntários, amadores ou mesmo pessoas mal preparadas. A docência é um campo profissional e o exercício do magistério conta, de longa data, com um saber que lhe é próprio".

A alteração da legislação foi marcada, também, por uma mudança na concepção do Estado, que assumiu a condição de avaliador, introduzindo o processo regular e sistemático de avaliação dos cursos de graduação e das instituições de ensino superior. Orientado pela lógica da qualidade e da excelência, passou a ter na avaliação da educação superior o principal objetivo, a partir da perspectiva de livre concorrência, universalização e competitividade. Ao implementarem o Exame Nacional de Cursos, o "Provão", ${ }^{6}$ como principal instrumento avaliativo por parte do Estado, as políticas públicas optaram por uma pedagogia da visão única, com padrões universais, capazes de uma comparabilidade competitiva que, por sua natureza, excluem formas alternativas de compreensão do conhecimento e de sua produção.

O Provão sofreu forte crítica durante toda a sua aplicação, que ocorreu até 2003, sendo, então, substituído, em 2004, pelo Exame Nacional de Desempenho de Estudantes (Enade), instituído pelo Sistema Nacional de Avaliação do Ensino Superior (Sinaes). Enquanto o Provão colocava o foco da avaliação no resultado quantitativo, com base em uma única prova de conhecimentos, relacionados ao curso no qual o aluno estava se formando, o Sinaes apresenta uma proposta de avaliação mais global, pois, além dos conhecimentos do aluno, também são avaliados o projeto pedagógico da instituição, o projeto dos cursos, o corpo docente, a infraestrutura e as atividades de pesquisa e extensão.

Em síntese, a universidade e tudo o que diz respeito a ela, nas últimas décadas, sofreu marcante pressão oriunda da legislação advinda das 
políticas públicas, com o objetivo de avaliar a qualidade do ensino superior e forçar sua adequação no sentido de formar profissionais qualificados para atender às novas exigências de um mercado cada vez mais complexo e globalizado. Ao mesmo tempo, registram-se, mais recentemente, iniciativas de democratização do acesso e a implantação de um sistema de avaliação que objetiva "olhar" a universidade e compreendê-la no diálogo entre a realidade e a necessidade local e global.

Não resta dúvida de que a universidade está condicionada pelos contextos onde está inserida e deve responder às exigências e urgências postas pela realidade. Em contrapartida, é igualmente necessário que ela não abra mão de sua sempre relativa autonomia, que se mantenha livre e aberta para que suas ações intencionais possam se dar de acordo com sua pertinência ética e social. Não basta à universidade ser contemporânea de seu tempo; ela precisa esforçar-se para estar adiante de seu tempo. Ela se transforma por efeito das mudanças que ocorrem em todas as esferas, mas também produz as transformações do mundo. Não deve, entretanto, perder a capacidade de se autodeterminar, tendo em vista seu objetivo original de ser a consciência crítica de si mesma e da sociedade.

Também é notório o estreitamento das relações entre a educação superior e as demandas econômicas, principalmente nos últimos anos, o que vem provocando problemas socioprofissionais e de sentido valorativo nem sempre fáceis de resolver. De um modo geral, é possível dizer que a educação superior vem se orientando menos para o desenvolvimento refletido da sociedade e para a formação da consciência crítica, e mais para a autonomização técnica e a competitividade individual, exigidas e incentivadas pelas forças produtivas da sociedade globalizada.

Diante dessa conjuntura, a sociedade vem perdendo, ao longo do tempo, parte de seu referencial valorativo. O que se percebe é o enfraquecimento dos processos de construção das subjetividades pelos quais os indivíduos se integram construtivamente na produção da vida social. Nesse contexto, não é de se estranhar que haja uma inversão de funções e que a educação superior se submeta ao mercado, mais que ao compromisso com a formação de cidadãos autônomos e com o aprofundamento da democracia.

Os elementos constitutivos das políticas econômicas aos poucos foram se sobrepondo aos que, anteriormente, orientavam as decisões e as ações educativas, havendo uma reorganização e uma centralização dos currículos, uma forte apologia da redução de custos, da avaliação dos sistemas educativos e, sutilmente, a construção de uma subjetividade embasada numa retórica que toma a lógica do mercado como referência da gestão educacional.

Essa lógica é alimentada por um processo de padronização que busca um pensamento único, como se todas as formas de produção e educação atingissem os mesmos produtos e atuassem com os mesmos atores sociais. É como se houvesse uma única forma de conhecimento e, portanto, uma única alternativa de formação. O problema reside no fato de que a validação de uma única forma de conhecimento, como afirma Santos (2000, p. 241), destrói as relações entre os objetos e, nessa trajetória, elimina 
as demais maneiras de se conceber o conhecimento: "o reverso da força da visão única é a capacidade para reconhecer visões alternativas". Esse fenômeno pode acabar no que ele chama de "epistemicídio", pois "a destruição de formas alternativas de conhecimento não é um artefato sem consequências, antes implica a destruição de práticas sociais e desqualificação de agentes sociais que operam de acordo com o conhecimento em causa" (p. 242).

Diante dessa realidade na qual a universidade está situada, frequentemente sendo colocada em cheque sua competência e sua legitimidade, é "natural" que ela atravesse uma "crise de identidade", como diz Dias Sobrinho (2005). Essa crise provoca, na universidade, um estado de insegurança quanto ao seu papel e suas tarefas na sociedade. Ciência e tecnologia, por serem fundamentais para o progresso moderno, historicamente foram e são centrais para a universidade. Entretanto, longe de serem atividades desinteressadas, porque não são neutras, podem resultar em consequências ambíguas que tanto podem alavancar o progresso quanto produzir a barbárie.

Conforme assinala Dowbor (2001, p. 24), "quando o conhecimento se torna um elemento-chave de transformação social, a própria importância da educação muda qualitativamente. Deixa de ser um complemento e adquire uma nova centralidade no processo". Isso é válido também para as universidades, pois, como esclarece Dias Sobrinho (2005, p. 81), apenas o conhecimento útil, gerador de riquezas materiais, tem valor de destaque nessa ótica: "É valorizada somente a instituição que produz conhecimento útil e/ou que forma profissionais com as competências e habilidades requeridas pelo mercado de trabalho".

Sendo assim, só têm importância econômica e política os conhecimentos que se relacionam com os processos de inovação tecnológica e produção industrial, competitividade e liderança no mercado, e que se situam nas unidades produtivas mais dinâmicas e valorizadas pela sociedade.

Essa lógica foi reforçada na medida em que o setor privado assumiu a condição de ser o maior empregador dos egressos das universidades. Ao serem pontuadas as dificuldades para assegurar o financiamento que atendesse às demandas da educação, o Estado considerou-se ineficiente para dar conta da gestão dos processos educativos, procurando, na retórica da autonomia, liberdade e autorregulação, transferir sua responsabilidade social para a livre iniciativa. O mercado surgiu, então, como personagem principal do discurso político oficial, quer no nível do Estado, quer das instituições, bem ao gosto das teorias neoliberais, que tanto pregam a ineficiência do setor público como algo incontornável.

Coube ao Estado, ao assumir a condição de Estado-Avaliador, reforçar o pilar da regulação, reinstituindo o processo de relações colonialistas na relação sujeito/objeto. Mesmo que esse processo possa trazer alguns resultados, aparentemente positivos, ao ensino superior, contraditoriamente, representa um perigo ao se tornar o padrão único, que provém de um ethos externo que impede, de certo modo, que as universidades sejam 
autoras de seu projeto político-pedagógico. Dessa forma, a universidade, que tanto aspirou pela sua autonomia, tanto buscou a sua condição de geradora de um pensamento livre, independente, ao se atrelar ao processo produtivo, acaba por aceitar que forças externas imponham o patamar de uma qualidade que não foi ela que escolheu.

As estratégias governamentais de convencimento da opinião pública, veiculadas pela mídia, vêm, aos poucos, acomodando a comunidade acadêmica aos novos padrões. Para tal condição, muito contribui o sentimento de impotência instaurado nas instituições perante o modelo avaliativo que se legitimou em legislações que impuseram obrigatoriedades e punições aos que dele se afastavam. A sensação de que não há alternativas ao modelo proposto favorece a absorção de seus pressupostos.

Nesse marco, as grandes discussões acadêmicas sobre a vocação da universidade, especialmente nos países em desenvolvimento, vão se perdendo e, em seu lugar, são colocadas energias para dar conta da qualidade imposta pelos processos avaliativos externos. O mais grave, entretanto, é reconhecer que esses processos não são analisados nas suas relações mais amplas, ou seja, articulados com o conceito de Estado.

Por isso, a compreensão das circunstâncias políticas que vêm definindo as condições objetivas do trabalho na universidade precisa ser referenciada em perspectivas mais largas e de maior profundidade. E, como alerta Cunha (2006), a rapidez com que são implementadas as novas diretrizes de atuação da universidade destoa do ritmo natural da reflexão acadêmica que, em geral, é mais lento e está acostumado a certo distanciamento dos fatos para empreender a sua interpretação.

Em tempos marcados por uma tendência para desvirtuar a vocação crítico-humanista da universidade, que corre o risco de, aos poucos, ser reduzida à tarefa de "formar indivíduos úteis" para atender às "necessidades sociais", em um mundo onde os postos de trabalho tornam-se cada vez mais raros e disputados, é preciso resistir ou combater o "abreviamento" de seu papel. É preciso assegurar seu princípio histórico, de instância crítica da sociedade, a partir de interesses humanos mais amplos democraticamente discutidos.

De uma forma ou de outra, todos os indivíduos são afetados pelas atividades científicas e pedagógicas produzidas e trabalhadas pelas instituições educativas. Como alerta Dias Sobrinho (2005, p. 95), "o que sempre deve estar em questão é o sentido da formação, especialmente nestes tempos dominados pela economia", uma vez que não podemos perder de vista que a formação humana envolve todo o campo social, pois alcança e têm reflexos em todos os setores da vida humana.

É ainda Dias Sobrinho (2005, p. 22) quem faz a reflexão sobre o que compete à educação na formação de cada membro de uma sociedade. Que tipo de formação é requerida em nossos tempos, se há tantas incertezas a respeito de quais são os valores primordiais, se não existe nenhuma segurança sobre os destinos da sociedade humana? Como conviver com um mundo tão avançado na capacidade de construir como de destruir? 
Não há dúvidas quanto aos notáveis avanços dos domínios técnicos e científicos ocorridos nos últimos tempos. Vale ressaltar os ganhos importantes que eles trouxeram para uma grande parcela da humanidade, entre os quais se destacam a maior longevidade, a ampliação da capacidade de produção de alimentos, a democratização das comunicações, entre tantas outras importantes conquistas. As novas tecnologias de informação e comunicação, principalmente, alteraram de alguma forma os limites espaciais e temporais, modificaram os modos de organização econômica, além de estenderem e de potencializarem as formas de relações humanas. No entanto, mesmo com os avanços, há no mundo uma crescente insegurança e um aumento significativo da miséria. Como afirma Dias Sobrinho (2005, p. 46), "desemprego, instabilidade dos mercados, fanatismos religiosos, culturais e econômicos, violência urbana, fome, guerra, droga são aspectos da barbárie que assustam grande parte da humanidade, neste que também é o período do mais avançado desenvolvimento tecnológico".

A educação superior tem o difícil desafio de enfrentar as contradições da regulação e da autonomia, dos avanços tecnológicos que trazem ao mesmo tempo benefícios para uma parcela da população e aumento da miséria para outra, que fica cada vez mais excluída desse universo de produção de bens e de serviços.

As ações humanas, sistematizadas em torno de processos instituídos, como é o caso da educação escolarizada, sendo tributárias da concepção de Estado, são portadoras tanto de forças regulatórias como emancipatórias. O equilíbrio entre elas seria desejável para que, garantindo a necessária sistematização, a regulação não fosse empecilho às energias emancipatórias. Entretanto, tal como ocorre nos espaços políticos e sociais da macroestrutura, o pilar do conhecimento regulação se sobrepõe ao pilar do conhecimento emancipação. "Estamos tão habituados a conceber o conhecimento como um princípio de ordem sobre as coisas e sobre os outros que é difícil imaginar uma forma de conhecimento que funcione como princípio de solidariedade, e esse é um desafio a ser enfrentado" (Santos, 2000, p. 30).

Apesar das tensões e das contradições, é indiscutível que a educação superior ocupa um lugar central no desenvolvimento cultural e econômico da vida contemporânea. Sendo assim, podemos dizer que o futuro vai depender, em boa parte, das respostas aos dilemas colocados à sociedade e por extensão à educação superior. Nesse sentido, torna-se fundamental a reflexão sobre as funções que ela exerce na construção da sociedade, não simplesmente por sua contribuição à formação técnica e profissional dos seus cidadãos, mas, sobretudo, em relação aos significados éticos e políticos que constituem parte essencial daquilo que é sua responsabilidade pública. A questão é, pois, encontrar o ponto adequado que torne virtuosa essa relação entre a sociedade mais ampla e a educação superior. O que esta não pode fazer é abrir mão de sua autonomia institucional e da liberdade acadêmica, que são condições essenciais da sua natureza.

Diante desse contexto, os desafios a serem enfrentados pela universidade são muitos e complexos. No início do Governo Lula, uma 
nova reforma universitária foi trazida para a agenda de discussão, depois de várias décadas. Esse projeto continua em discussão na sociedade e no Congresso Nacional. Mais recentemente, foi aprovado o Programa Universidade para Todos (ProUni). O Programa é considerado o maior programa de bolsas de estudo da história da educação brasileira. Criado pelo governo federal em 2004 e institucionalizado pela Lei no 11.096, de 13 de janeiro de 2005, possibilita o acesso de milhares de jovens de baixa renda à educação superior. Tem como finalidade a concessão de bolsas de estudos integrais e parciais, a estudantes de cursos de graduação e sequenciais de formação específica, oferecendo àquelas instituições privadas de educação superior que aderiram ao programa, em contrapartida, isenção de alguns tributos. Ainda que de forma tímida, conforme expõe Corbucci (2004, p. 698), constitui-se uma iniciativa "de redistribuição indireta de renda, ao transferir recursos de isenção fiscal a estratos populacionais mais pobres, já que tais recursos, caso fossem arrecadados, não beneficiariam necessariamente esses grupos sociais".

Trindade (2004) apresenta algumas questões emblemáticas que uma proposta deve ser capaz de responder:

1) Qual o papel do Estado, no contexto da economia mundializada, para enfrentar a reforma de um sistema público/privado tão desequilibrado?

2) Qual o nível de massificação aceitável para o sistema público de educação superior, para que ele possa cumprir suas funções inovadoras na pesquisa fundamental e aplicada para as novas economias?

3) Qual a função estratégica da universidade na construção de um projeto de nação soberana e inserida na competição internacional pela geração de conhecimentos científicos e tecnológicos?

Ao analisar a proposta de reforma, que está em curso em nosso País, o autor argumenta que ela poderá levar ao aprofundamento da democracia, caso atenda a algumas exigências. Entre elas, cita a revalorização do papel do sistema de educação superior no cumprimento de sua real missão acadêmica e social, de forma a contribuir com a formação de profissionais competentes, cientistas, humanistas e artistas, enfim, de todos os cidadãos, buscando o desenvolvimento econômico, social e cultural da humanidade. Só assim, em suas palavras, "a velha bandeira da reforma universitária da democratização pela ampliação do acesso ao ensino superior precisa continuar viva, expandindo o sistema de todas as formas sob o impulso e a supervalorização do poder público" (Trindade, 2004, p. 834).

Para enfrentar esses desafios, é necessário que os protagonistas que vivenciam e que são responsáveis pelo processo de formação estejam muito bem preparados. Não se pode fazer uma boa educação em nível superior sem sólidos investimentos na formação dos professores universitários. Devemos lembrar que a formação do professor de magistério superior é, também, inseparável da formação do pesquisador, embora nem todos os 
professores tenham esse perfil e sigam esse caminho. Ensino e pesquisa voltados às necessidades da sociedade cumprem sua função social de extensão.

Para que a universidade possa garantir sua autonomia, os professores, necessariamente, precisam ser capazes de acompanhar crítica e criativamente a evolução da sociedade e estarem aptos para produzir as condições de um futuro sempre melhor para eles mesmos, para seus alunos e para toda a sociedade.

Há sérios problemas de deficiências na formação e no modo de atuação de muitos professores, que, por isso mesmo, devem estar direta ou indiretamente sofrendo pressões para dar conta dessas novas funções e das capacidades exigidas na educação superior, causadas pelo desenvolvimento acelerado das novas tecnologias, pelo grande acúmulo de conhecimentos nas mais diversas áreas, pelo surgimento de novos instrumentos de trabalho e pela renovação de outros. Nem todos os professores receberam formação pedagógica e científica, à altura das exigências da sociedade, para o exercício profissional do magistério superior.

Um dos aspectos essenciais a se considerar é a necessidade de que a formação seja tecnicamente consistente e atualizada, mas que supere o imediatismo da capacitação técnica. É bom lembrar que a grande e principal missão do professor continua e continuará sendo a de formar, e essa é sempre uma tarefa muito complexa, completa e que extrapola a ideia de transmissão de um punhado de informações e de desenvolvimento de competências e de habilidades técnicas.

\section{Considerações finais}

Ainda que se localize uma tendência atual para enfatizar mais a aprendizagem do que o ensino e a valorizar a aprendizagem ao longo da vida, há de se registrar a importância da docência, pois, como afirma Dias Sobrinho (2005, p. 96), "mesmo assim o papel do professor continua sendo de grande importância, não necessariamente como o proprietário do saber, mas, sobretudo, como organizador, animador e, ainda, referência intelectual e, quem sabe, moral".

Outra questão que merece destaque é o papel que a avaliação institucional pode ter na formação humana integral dos sujeitos que fazem educação. Para Dias Sobrinho e Ristoff (2002), os valores como justiça social, pertinência, cidadania, independência intelectual, liberdade, solidariedade, igualdade, entre outros, fornecem linhas de ação para o processo de construção da sociedade humana, e estas devem ser levadas em conta, quando se pretende avaliar para a emancipação e a cidadania. Dizem os autores que o que devemos esperar da educação é que, no mínimo, promova com muita competência a técnica enraizada na ética, e que isso efetivamente resulte na melhoria da qualidade de vida social e individual.

A avaliação que se faz fundada nesses valores confere prioridade ao sujeito e à subjetividade. Preocupa-se com a formação, no sentido de 
que os cidadãos, e nesse caso os professores, à medida que se educam continuamente, tenham melhores condições para participar mais crítica e produtivamente da produção do mundo humano. Nesse sentido, a avaliação institucional é entendida como uma ação que pode possibilitar ao professor, como sujeito crítico, autônomo e situado historicamente, continuamente construir-se docente no ensino superior.

A partir das reflexões sobre a trajetória da universidade brasileira podemos compreender que esses passos, avanços, recuos e crises condicionaram e deixaram marcas que caracterizam o atual sistema de ensino superior em nosso País. O importante é perceber que as ideias não morrem e que, dialeticamente, os homens continuam construindo o novo a partir das lições internalizadas e da reflexão sobre as experiências vivenciadas no passado. Portanto, a universidade é uma instituição social que, antes de ser pronta e acabada, continua sendo pensada, discutida, construída, ressignificada em cada tempo, em cada contexto, tendo em vista os seus atores sociais, as bases epistemológicas e os condicionantes culturais, políticos e econômicos que a produzem.

\section{Referências bibliográficas}

ARAÚJO, Elizabeth de Melo Bomfim. Reforma universitária: suas causas e consequências. In: TUBINO, Manoel José Gomes (Org.). A universidade ontem e hoje. São Paulo: Ibrasa, 1984.

BRASIL. Decreto $n^{\circ} 14.343$, de 7 de setembro de 1920. Approva o Regimento da Universidade do Rio de Janeiro. Disponível em: < http:// www6.senado.gov.br/legislacao/ListaPublicacoes.action?id=48093>. Acesso em: 17 maio 2006.

Decreto $n^{\circ} 11.530$, de março de 1915. Reforma Carlos

Maximiliano. Reorganiza o ensino secundário e o superior na Republica. Disponível em: <http://www6.senado.gov.br/legislacao/ ListaPublicacoes.action?id=52597> . Acesso em: 18 maio 2006.

Decreto $n^{\circ}$ 8.659, de 5 de abril de 1911. Approva a lei Organica do Ensino Superior e do Fundamental na Republica. Disponível em: <http://www6.senado.gov.br/legislacao/ ListaPublicacoes.action?id=58698 > . Acesso em: 16 maio 2006.

Lei no 5.539, de 18 de março de 1915. Modifica dispositivos da Lei número 4.881-A, de 6 de dezembro de 1965, que dispõe sobre o Estatuto do Magistério Superior, e dá outras providências. Disponível em: <http://www6.senado.gov.br/legislacao/ListaPublicacoes. action?id=118524> . Acesso em: 18 maio 2006. 
BRASIL. Lei $n^{\circ}$ 5.540, de 28 de novembro de 1968. Fixa normas de organização e funcionamento do ensino superior e sua articulação com a escola média, e dá outras providências. Disponível em: < http:// www6.senado.gov.br/legislacao/ListaPublicacoes. action?id=102363>. Acesso em: 18 maio 2006.

. Lei no 11.096, de 13 de janeiro de 2005. Institui o Programa Universidade para Todos - PROUNI, regula a atuação de entidades beneficentes de assistência social no ensino superior; altera a Lei ${ }^{\circ}$ 10.891, de 9 de julho de 2004, e dá outras providências. Disponível em: < http://www.andes.org.br/imprensa/Uploads/LEI\%2011096.pdf> . Acesso em: 17 maio 2006.

. Lei no 9.394, de 20 de dezembro de 1996. Estabelece as diretrizes e bases da educação nacional. Disponível em: <http://www. portal.mec.gov.br/setec/arquivos/pdf1/proejalei9394.pdf > . Acesso em: 17 maio 2006.

CARNEIRO, João Marinonio Aveiro; CARNEIRO, Iara Elfriede Enke. Metodologia do ensino superior. Rio de Janeiro: Folha Carioca, 2000.

CHAUÍ, Marilena de Souza. Escritos sobre a universidade. São Paulo: Ed. da Unesp, 2001.

CORBUCCI, Paulo Roberto. Financiamento e democratização do acesso à educação superior no Brasil: da deserção do Estado ao projeto de reforma. In: Revista Educação \& Sociedade. Campinas-SP, v. 25, n. 88, especial, p. 677-701, out. 2004.

CUNHA, Luiz Antonio. Reforma universitária em crise: gestão, estrutura e território. Avaliação, Rede de Avaliação Institucional da Educação Superior (Raies), v. 3, n. 2, jun. 1998.

CUNHA, Maria Isabel da (Org.). Pedagogia universitária: energias emancipatórias em tempos neoliberais. Araraquara-SP: Junqueira \& Martins, 2006.

CURY, Carlos Roberto Jamil. Políticas de educação superior e a prática pedagógica: um quadro do ordenamento jurídico e suas repercussões. In: SILVA, Aida Maria Monteiro et al.(Org.). Anais... Encontro Nacional de Didática e Prática de Ensino (Endipe). Recife: Endipe, 2006.

DIAS SOBRINHO, José. Dilemas da educação superior no mundo globalizado: sociedade do conhecimento ou economia do conhecimento? São Paulo: Casa do Psicólogo, 2005. 
DOWBOR, Ladislau. Tecnologias do conhecimento: os desafios da educação. Petrópolis: Vozes, 2001.

FÁVERO, Maria de Lourdes de Albuquerque. Universidade do Brasil: das origens à construção. Rio de Janeiro: Ed. da UFRJ, Inep, 2000.

HAWERROTH, Jolmar Luis. A expansão do ensino superior nas universidades do sistema fundacional catarinense. Florianópolis: Insular, 1999.

LUCKESI, Cipriano Carlos et al. Fazer universidade: uma proposta metodológica. São Paulo: Cortez, 1985.

MAUÉS, Olgaíses. Implicações das políticas de educação superior no trabalho docente. In: SILVA, Aida Maria Monteiro et al. (Org.). Anais... Encontro Nacional de Didática e Prática de Ensino (Endipe). Recife: Endipe, 2006.

NAGLE, Jorge. Educação e sociedade na Primeira República. São Paulo: Edusp, 1974.

OLIVE, Arabela Campos. História da educação superior no Brasil. In: SOARES, Maria Suzana Arrosa (Org.). A educação superior no Brasil. Brasília: Capes, 2002.

RIBEIRO, Darcy. A universidade necessária. 2. ed. Rio de Janeiro: Paz e Terra, 1975.

RISTOFF, Dilvo Ilvo. Universidade em foco: reflexões sobre a educação superior. Florianópolis: Insular, 1999.

ROMANELLI, Otaíza de Oliveira. História da educação no Brasil. 1930-1973, Petrópolis: Vozes, 1978.

SANTOS, Boaventura de Sousa. Pela mão de Alice: o social e o político na pós-modernidade. 2. ed. São Paulo: Cortez, 1999.

SANTOS, Milton. Por uma outra globalização: do pensamento único à consciência universal. 2. ed. Rio de Janeiro: Record, 2000.

SCHWARTZMAN, Simon (Org.). Universidades e instituições científicas no Rio de Janeiro. Brasília: CNPq, 1982.

SILVEIRA, Nádia Dumara Ruiz. Universidade Brasileira: a intenção da extensão. São Paulo: Loyola, 1987.

TEIXEIRA, Anísio. Educação no Brasil. São Paulo: Companhia Editora Nacional, 1969. 
TEIXEIRA, Anísio. Ensino Superior no Brasil: análise e interpretação de sua evolução até 1969. Rio de Janeiro: Fundação Getúlio Vargas, 1989.

TRINDADE, Hélgio. A república em tempos de reforma universitária: o desafio do governo Lula. Educação \& Sociedade, Campinas-SP, v. 25, n. 88, p. 819-844, especial, out. 2004.

VENÂNCIO FILHO, Alberto. Das arcadas ao bacharelismo: 150 anos de ensino jurídico no Brasil. São Paulo: Secretaria da Cultura, Ciência e Tecnologia, 1977.

WANDERLEY, Luiz Eduardo W. O que é universidade? São Paulo: Brasiliense, 1983.

Gildo Volpato, doutor em Educação pela Universidade do Vale do Rio dos Sinos (Unisinos), é professor do Programa de Pós-Graduação em Educação da Universidade do Extremo-Sul Catarinense (Unesc).

gildo@unesc.net

Recebido em 20 de março de 2010.

Aprovado em 14 de setembro de 2011. 